\title{
Charactenization of Reactive Oxygen/ Nitrogen Species Produced in PBS and DMEM by Air DBD Plasma Treatments
}

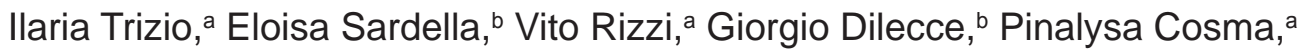 \\ Michael Schmidt, ${ }^{c}$ Thomas von Woedtke, ${ }^{c}$ Roberto Gristina,,${ }^{b,}$ \& Pietro Favia ${ }^{a, b}$ \\ aDepartment of Chemistry, University of Bari "Aldo Moro," Bari, Italy; 'NANOTEC Institute, CNR, \\ Bari, Italy; 'Leibnitz Institute for Plasma Science and Technology (INP), Greifswald, Germany \\ *Address all correspondence to: Roberto Gristina, Nanotec Institute, CNR, c/o Department of Chemistry, University of \\ Bari “Aldo Moro”, Via Orabona 4, Bari, Italy, E-mail: roberto.gristina@cnr.it
}

\begin{abstract}
Atmospheric pressure air dielectric barrier discharges were applied to phosphate-buffered saline and complete Dulbecco's modified Eagle medium (DMEM) supplemented with 10\% fetal bovine serum to investigate their oxidative chemical modifications induced in liquids that are relevant for cell culture experiments in the field of Plasma Medicine. The study mainly identified long-living reactive species. Hydrogen peroxide, superoxide anion radicals, and nitrite and nitrate ions were detected in DMEM. The density of the reactive species was correlated with the energy dose delivered to the liquids by the discharges.
\end{abstract}

KEY WORDS: dielectric barrier discharge, plasma on liquids, culture medium, phosphate buffer serum, hydrogen peroxide, superoxide anion, nitrite, nitrate

\section{INTRODUCTION}

Nonequilibrium plasmas at low pressure and atmospheric pressure (AP) are acknowledged today as advanced, versatile tools for surface modification processes of materials for biomedical $^{1-5}$ and other applications. Plasma processes also have been investigated, largely for the sterilization of materials and, most recently, for therapeutic purposes (plasma medicine). ${ }^{5,6}$ It was recently shown, for example, that wound healing, dentistry, and cancer treatments can potentially benefit from the direct application of air plasmas at AP onto living tissues..$^{7-9}$ The treatments of living matter with air plasmas at AP are strongly affected by the presence of liquids (water, culture media, exudate, blood, etc.) in vivo and in vitro. A full understanding of the cascade reactions triggered by the plasma in the liquids is yet to be achieved; it is clear, though, that many short- and long-lived species are formed in waterbased liquids upon exposure to plasma, depending on the plasma source and on the composition of both the feed gas and the liquid. It is also clear that plasma-generated reactive oxygen species (ROS) and reactive nitrogen species (RNS) affect cells and tissues more than other plasma species. ${ }^{10-14}$ For this work, phosphate-buffered saline (PBS) and the complete culture medium, Dulbecco's modified Eagle medium (DMEM) plus 10\% fetal bovine serum (FBS), were exposed to 3 dielectric barrier discharges (DBDs) in air characterized by different energy doses; superoxide $\left(\mathrm{O}_{2}^{-}\right)$, hydrogen peroxide $\left(\mathrm{H}_{2} \mathrm{O}_{2}\right)$, nitrite $\left(\mathrm{NO}_{2}^{-}\right)$, and nitrate $\left(\mathrm{NO}_{3}^{-}\right)$species were generated in the liquids as a function of the energy delivered. The redox reaction involving cytochrome $\mathrm{c}$ was used to detect $\mathrm{O}_{2}^{-}$anions. $\mathrm{H}_{2} \mathrm{O}_{2}$ was revealed 
with a method based on 2,7-dichlorofluorescein (DCFH), kept selective by means of peroxidase enzyme. Colorimetric assays for $\mathrm{NO}_{2}{ }^{-}$and $\mathrm{NO}_{3}{ }^{-}$, already applied to $\mathrm{PBS}$ in our previous studies, ${ }^{15}$ were used here in DMEM $+10 \% \mathrm{FBS}$ within 5 min. and 1 hour after the DBD treatment.

\section{MATERIALS AND METHODS}

\section{A. Experimental Setup}

An air DBD device with a parallel electrode geometry was designed to be mounted on top of 60-mm-diameter cell culture Petri dishes, which were filled with $3 \mathrm{~mL}$ of PBS or supplemented DMEM. The distance between the ground electrode and the liquid surface was $2 \mathrm{~mm}$. The high-voltage (HV) copper plate electrode was covered with 1-mm-thick glass; the ground stainless steel mesh was spaced from the glass with a 1-mm-thick Teflon ring. The distance between the HV and the ground electrodes was $4 \mathrm{~mm}$. DBDs were ignited with $13-\mathrm{kV}$ peak-to-peak voltage at $6 \mathrm{kHz}$ close to, but with no contact with, the liquids. Treatment time and plasma ignition time ( $t_{\text {on }}$; period, $\left.100 \mathrm{~ms}\right)$ varied. According to our previous work, the 3 different experimental conditions investigated were set up with reference to the energy dose delivered to samples. ${ }^{15}$

ROS/RNS detection in PBS and DMEM $+10 \% \mathrm{FBS} \mathrm{NO}_{2}^{-}$ions were detected using the Griess assay (Spectroquant test kit), whereas $\mathrm{NO}_{3}{ }^{-}$ions were detected via a colorforming reaction with 2,6-dimethylphenol (Spectroquant test kit). The detection of $\mathrm{O}_{2}^{-}$ was based on the reduction of ferricytochrome $\mathrm{c}$ to ferrocytochrome $\mathrm{c}\left(\mathrm{Cyt} \mathrm{Fe}^{2+}\right)^{16}$; the generation of $\mathrm{Cyt} \mathrm{Fe}^{2+}$ increases the absorbance intensity at 520 and $550 \mathrm{~nm}$. A stock solution of horse heart cytochrome c (5 mg/mL; Sigma Aldrich) was prepared and 400 $\mu \mathrm{L}$ were added to the treated liquid. To better elucidate the selectivity of the method used to detect $\mathrm{O}_{2}^{-}$, superoxide dismutase (SOD) enzyme, a catalyst for the conversion of $\mathrm{O}_{2}^{-}$into $\mathrm{H}_{2} \mathrm{O}_{2}$ and $\mathrm{O}_{2}$, was also added ( $40 \mu \mathrm{L}$ of $50 \mu \mathrm{mol} / \mathrm{L}$ stock $\mathrm{SOD}$ solution) to untreated and treated liquids.

The detection of $\mathrm{H}_{2} \mathrm{O}_{2}$ was based on DCFH, commonly used in the intracellular environment, where peroxidase catalyzes the reaction. ${ }^{17,18}$ When this assay was applied to PBS (Sigma Aldrich) and DMEM (Sigma Aldrich) supplemented with 10\% FBS (Sigma Aldrich), peroxidase enzyme has to be added to keep the reaction selective toward $\mathrm{H}_{2} \mathrm{O}_{2}{ }^{18}$ DCFH is easily oxidized by $\mathrm{H}_{2} \mathrm{O}_{2}$ and turns to highly fluorescent species with an emission peak at $535 \mathrm{~nm}$ (excitation wavelength $[\lambda e c c]=485 \mathrm{~nm}$ ). A $10 \mathrm{mmol} / \mathrm{L}$ methanolic stock solution of DCFH diacetate (Sigma Aldrich) was prepared. To hydrolyze DCFH diacetate, $2 \mu \mathrm{L}$ of a $100 \mu \mathrm{mol} / \mathrm{L}$ carbonic anhydrase solution (Sigma Aldrich) were added. Finally, $1.4 \mu \mathrm{L}$ of $60 \mu \mathrm{mol} / \mathrm{L}$ horseradish peroxidase (Sigma Aldrich) were added before adding $750 \mu \mathrm{L}$ of the untreated or plasma-treated sample.

All detections were performed with ultraviolet-visible spectrophotometers. The $\mathrm{pH}$ of the 2 buffered liquids did not change from their initial values (7.4 for PBS; 7.5 for DMEM) after the 3 different treatments. 


\section{RESULTS AND DISC USSION}

Figure $1 \mathrm{~A}$ and $\mathrm{B}$ shows, respectively, the concentration of $\mathrm{NO}_{2}^{-}$and $\mathrm{NO}_{3}{ }^{-}$detected in DMEM $+10 \%$ FBS before and after the 3 different plasma treatments. Increasing the energy dose delivered by the plasma resulted in a larger amount of both species in treated complete DMEM. Similar findings were obtained in PBS, as shown in our previous paper. ${ }^{15}$ Measurements were also repeated $1 \mathrm{~h}$ after exposure to the plasma, and the concentration of $\mathrm{NO}_{3}^{-}$was increased, whereas that of $\mathrm{NO}_{2}^{-}$had decreased. These findings give indications of the time evolution of the DBD-triggered chemistry involving nitrogen-containing species. Such behavior after discharge was revealed by Lukes et al. ${ }^{19}$ in air-plasma-treated liquid at various acidic $\mathrm{pH}$ values. In particular, the possible production of peroxynitrite was determined by kinetic analysis of the pseudo-second order between $\mathrm{H}_{2} \mathrm{O}_{2}$ and $\mathrm{NO}_{2}^{-}$. The method was found to be valid even when decreasing the acidity of the solution. ${ }^{19}$
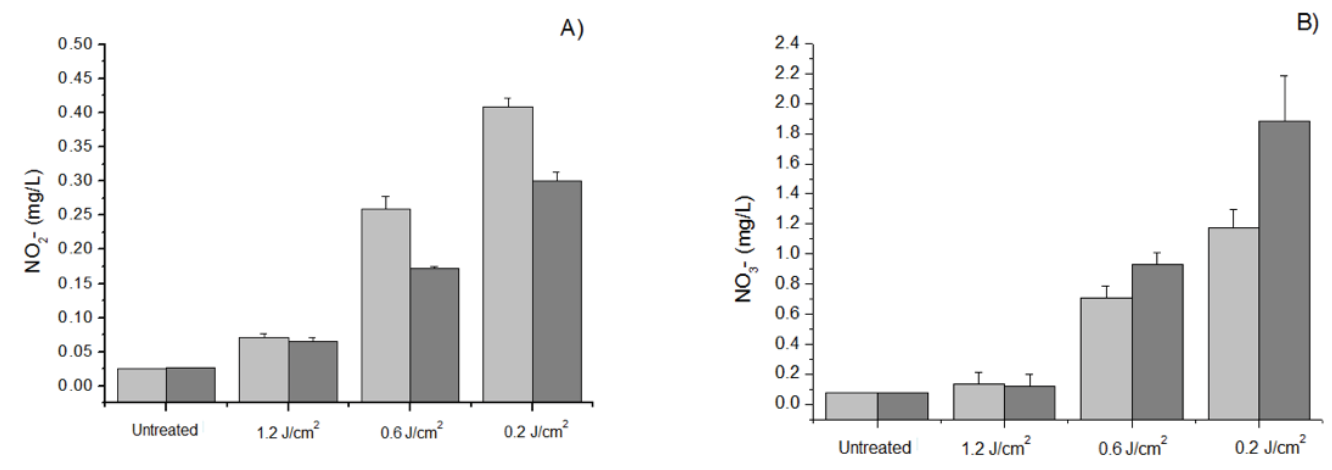

FIG. 1: Nitrite ion $\left(\mathrm{NO}_{2}^{-}\right)(\mathrm{A})$ and nitrate ion $\left(\mathrm{NO}_{3}^{-}\right)$(B) concentrations in untreated and plasmatreated Dulbecco's modified Eagle medium $+10 \%$ fetal bovine serum within 5 min. (light grey bars) and 1 hour after the plasma treatment (dark grey bars).

Fluorescence spectra of activated DCFH were registered for both untreated and plasma-treated PBS and DMEM supplemented with 10\% FBS; as shown in Fig. 2, the fluorescence peak at $535 \mathrm{~nm}$ is very low for the untreated samples, whereas in both liquids it increases with the energy dose of plasma. A $0.2 \mathrm{~J} / \mathrm{cm}^{2}$ treatment increased the signal up to 250 arbitrary units (AU) in PBS and up to $220 \mathrm{AU}$ in DMEM $+10 \% \mathrm{FBS}$. Both liquids, treated with $0.6 \mathrm{~J} / \mathrm{cm}^{2}$ air DBDs, shown an almost comparable fluorescence around $300 \mathrm{AU}$; after the $1.2 \mathrm{~J} / \mathrm{cm}^{2}$ treatment, the signal increases to $390 \mathrm{AU}$. This finding attests to the increased production of $\mathrm{H}_{2} \mathrm{O}_{2}$ with an increasing plasma energy dose. It is worth noting that without adding peroxidase, the same detection protocol could not detect $\mathrm{H}_{2} \mathrm{O}_{2}$ in the plasma-treated samples, leading to fluorescence signals that were almost comparable to those of the untreated samples (data not shown).

Volume 6, Issue 1, 2016 

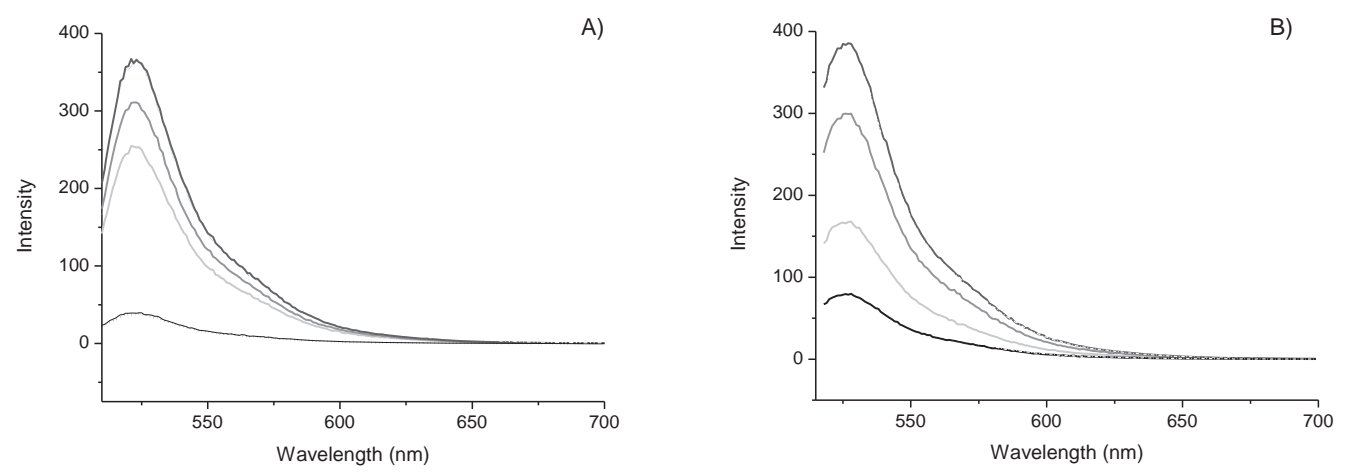

FIG. 2: Fluorescence spectra of activated 2,7-dichlorofluorescein of untreated and treated phosphate-buffered saline (A) and Dulbecco's modified Eagle medium $+10 \%$ fetal bovine serum (B). Black lines refer to untreated samples; light grey lines, liquids treated at $0.2 \mathrm{~J} / \mathrm{cm}^{2}$; grey lines, liquids treated at $0.6 \mathrm{~J} / \mathrm{cm}^{2}$; and dark grey lines, liquids treated at $1.2 \mathrm{~J} / \mathrm{cm}^{2}$. AU, arbitrary units.

For the detection of $\mathrm{O}_{2}^{-}$, the reduction of cytochrome $\mathrm{c}$ was monitored in PBS and in DMEM supplemented with 10\% FBS after adding ferricytochrome c; Fig. 3A and B shows the relative absorbance spectra for PBS and supplemented DMEM, respectively. Interestingly, in plasma-treated DMEM, the resulting production of $\mathrm{Cyt} \mathrm{Fe} 2+$, highlighted by a peak at $550 \mathrm{~nm}$, was more evident when the energy dose of the plasma was increased; however, this was not found in PBS. Such evidence allows us to hypothesize that the production of $\mathrm{O}_{2}^{-}$in DMEM is probably cannot be ascribed only to the plasma. As emphasized by Wardman, ${ }^{20}$ side reactions involving thiols or thiol-containing molecules (e.g., glutathione) generating $\mathrm{O}_{2}^{-}$probably occur in complex media such as DMEM. ${ }^{19,21}$ In fact, glutathione, a strong antioxidant, is absent in PBS but is commonly present in both cell culture media and FBS. Preliminary experiments devoted to better elucidating the possible role played by glutathione and thiol-containing molecules in $\mathrm{O}_{2}{ }^{-}$production are in progress to confirm this hypothesis.

The insight of the presence of $\mathrm{O}_{2}^{-}$was also strengthened by the kinetics of the cytochrome $\mathrm{c}$ reduction up to 1 hour after the plasma (Fig. 3C). Indeed, interesting results were obtained when the SOD enzyme was added; because of the dismutation of the $\mathrm{O}_{2}{ }^{-}$ ions generated in the treated samples and the consequent production of $\mathrm{H}_{2} \mathrm{O}_{2}$, a decrease of the 550-nm peak intensity was observed, thus confirming the presence of such species in the plasma-treated liquids.

In our recent paper ${ }^{15}$ we showed the interesting effects of using plasma-treated DMEM for a limited duration on reducing or stimulating the viability of different cells (Saos-2, an osteoblast cell line, and primary ovine bone marrow stem cells) as a function of the energy dose delivered by the plasma to the medium and, ultimately, as a function of the ROS/RNS developed in it. We are aware that most of the promising successes of plasmas in wound healing (e.g., enhancing the viability of certain cells) and cancer treatments (e.g., triggering the death of cancer cells) are the result of the action of ROS/ 

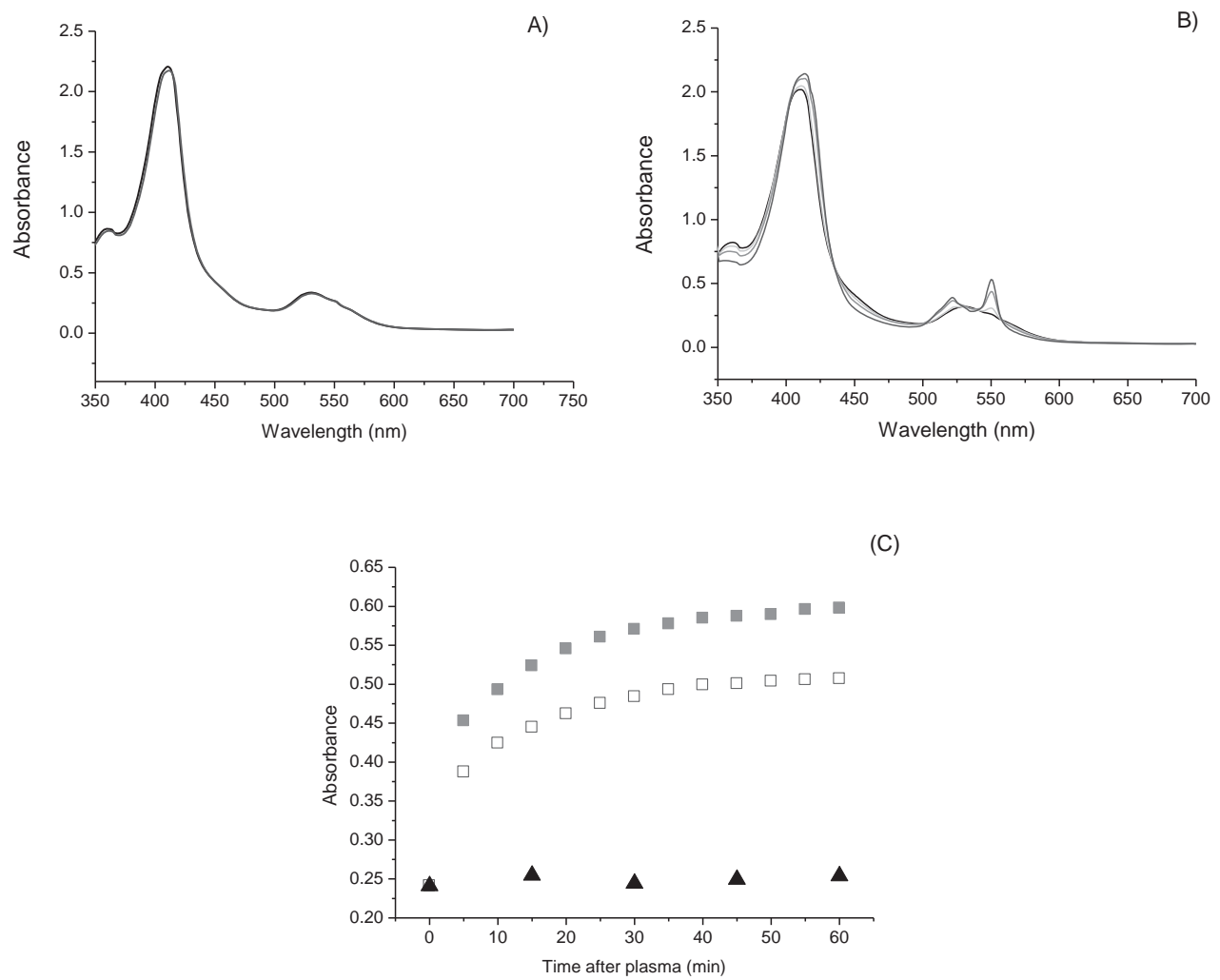

FIG. 3: Absorbance spectra of cytochrome $\mathrm{c}$ when added to untreated and treated phosphatebuffered saline (A) and Dulbecco's modified Eagle medium + 10\% fetal bovine serum (DMEM + $10 \% \mathrm{FBS}$ ) (B). Black lines refer to untreated samples; light grey lines, the $0.2 \mathrm{~J} / \mathrm{cm}^{2}$-treated samples; grey lines, $0.6 \mathrm{~J} / \mathrm{cm}^{2}$-treated samples; dark grey lines, $1.2 \mathrm{~J} / \mathrm{cm}^{2}$-treated samples. (C) Evolution of the cytochrome c 550-nm peak after dielectric barrier discharges in untreated DMEM + $10 \%$ FBS $(\boldsymbol{\Lambda}), 1.2 \mathrm{~J} / \mathrm{cm}^{2}$-treated $(\square)$, and $1.2 \mathrm{~J} / \mathrm{cm}^{2}$-treated with superoxide dismutase added ( $\square$ ).

RNS created by the plasma in the liquids surrounding the cells both in vitro and in vivo $^{7-10}$; thus we strongly believe that a full understanding and control (by means of the plasma parameters) of the generation reactions of ROS/RNS in cell culture media and physiological exudates is essential for boosting the use of plasmas as therapeutic tools in hospitals.

\section{CONCLUSIONS}

In this work 2 different buffered liquids, PBS and DMEM + 10\% FBS, were analyzed after being exposed to air DBD to gain insights into both the potential of the plasma to produce ROS/RNS and the key role played by the liquid composition in this process. Long-lived species such as $\mathrm{NO}_{2}^{-}, \mathrm{NO}_{3}^{-}$, and $\mathrm{H}_{2} \mathrm{O}_{2}$ were detected in both liquids. $\mathrm{O}_{2}^{-}$was

Volume 6, Issue 1, 2016 
detected only in DMEM $+10 \%$ FBS, leading us to hypothesize some role for thiolcontaining compounds in generating such species when, triggered by plasma. Deeper investigations are clearly needed to sharply quantify all active species generated in buffers and culture media as a function of the plasma exposure parameters, and to understand and unambiguously correlate the interaction of each kind of active species with various cells and tissues, with the aim to exploit fully the high potential of cold plasmas for therapeutic use.

\section{ACKNOWEDGMENTS}

The projects RINOVATIS (RIgenerazione di tessuti Nervosi e Osteocartilaginei mediante innOVativi Approcci di TISsue engineering PON 02_00563_348479 [PON MIUR]), LIPP (Laboratorio Industriale Pugliese dei Plasmi [Rete di Laboratorio 51, Regione Puglia]), RIGENERA (Scaffold innovativi per la riparazione e la rigenerazione dei tessuti biologici [partnernariati Regione Puglia]), SISTEMA(Laboratorio per lo sviluppo integrato delle scienze e delle tecnologie dei materiali avanzati e per i dispositivi innovativi [PON MIUR]), and EC COST action MP1101 are acknowledged for funding and supporting this research. The authors thank S. Cosmai (NANOTEC CNR Bari) and D. Benedetti (Univ. Bari) for providing technical support.

\section{REFERENCES}

1. Siow KS, Britcher L, Kumar S, Griesser HJ. Plasma methods for the generation of chemically reactive surfaces for biomolecule immobilization and cell colonization - a review. Plasma Process Polym. 2006;3:392-418.

2. Domingos M, Intranuovo F, Gloria A, Gristina R, Ambrosio L, Bartolo PJ, Favia P. Improved osteoblast cell affinity on plasma-modified 3-D extruded PCL scaffolds. Acta Biomater 2013;9:5997-6005.

3. Intranuovo F, Gristina R, Brun F, Mohammadi S, Ceccone G, Sardella E, Rossi F, Tromba T, Favia P. Plasma modification of PCL porous scaffolds fabricated by solvent-casting/particulate-leaching for tissue engineering. Plasma Process Polym. 2014;11:184-95.

4. Da Ponte G, Sardella E, Fanelli F, d'Agostino R, Gristina R, Favia P. Plasma deposition of PEO-like coatings with aerosol-assisted dielectric barrier discharges. Plasma Process Polym. 2012;9:1176-83.

5. Laroussi M. From killing bacteria to destroying cancer cells: 20 years of plasma medicine. Plasma Process Polym. 2014;11:1138-41.

6. Weltmann KD, Brandenburg R, von Woedtke T, Ehlbeck J, Foest R, Stieber M, Kindel E. Antimicrobial treatment of heat sensitive products by miniaturized atmospheric pressure plasma jets (APPJs). J Phys D Appl Phys 2008;41(19): 194008-13.

7. von Woedtke T, Reuter S, Masur K, Weltmann KD. Plasmas for medicine. Phys Rep. 2013;530: 291-320.

8. Graves DB. Reactive species from cold atmospheric plasma: implications for cancer therapy. Plasma Process Polym. 2014;11:1120-7.

9. Vandamme M, Robert E, Lerondel S, Sarron V, Ries D, Dozias S, Sobilo J, Gosset D, Kieda C, Legrain B, Pouvesle JM, Le Pape A. ROS implication in a new antitumor strategy based on non-thermal plasma. Int J Cancer. 2012;130:2185-94.

10. Traylor MJ, Pavlovich MJ, Karim S, Hait P, Sakiyama Y, Clark DS, Graves DB. Long-term antibacterial efficacy of air plasma-activated water. J Phys D Appl Phys. 2011;44:472001.

11. Lukes P, Dolezalova E, Sisrova I, Clupek M. Aqueous-phase chemistry and bactericidal effects from 
an air discharge plasma in contact with water: evidence for the formation of peroxynitrite through a pseudo-second-order post-discharge reaction of $\mathrm{H}_{2} \mathrm{O}_{2}$ and $\mathrm{HNO}_{2}$. Plasma Sources Sci Technol. 2014;23:015019.

12. Ikawa S, Kitano K, Hamaguchi S. Effects of $\mathrm{pH}$ on bacterial inactivation in aqueous solutions due to low-temperature atmospheric pressure plasma application. Plasma Process Polym. 2010;7:33-42.

13. Machala Z, Tarabova B, Hensel K, Spetlikova E, Sikurova L, Lukes P. Formation of ROS and RNS in water electro-sprayed through transient spark discharge in air and their bactericidal effects. Plasma Process Polym. 2013;10:649-59.

14. Gomes A, Fernandes E, Lima JL. Fluorescence probes used for detection of reactive oxygen species. J Biochem Biophys Methods. 2005;60:45-80.

15. Trizio I, Sardella E, Francioso E, Dilecce G, Rizzi V, Cosma P, Schmidt M, Hänsch M, von Woedtke T, Favia P, Gristina R. Investigation of air-DBD effects on biological liquids for in-vitro studies on eukaryotic cells. Clin Plasma Med. 2015;3:62-71.

16. Chen CJ, West AC, Cropek DM, Banta S. Detection of the superoxide radical anion using various alkanethiol monolayers and immobilized cytochrome C. Anal Chem. 2008;80:9622-9.

17. Wang H, Joseph JA. Quantifying cellular oxidative stress by dichlorofluorescein assay using microplate reader. Free Radic Biol Med. 1999;27:612-6.

18. Rota C, Chignell CF, Mason RP. Evidence for free radical formation during the oxidation of $2^{\prime}-7^{\prime}-$ dichlorofluorescin to the fluorescent dye $2^{\prime}-7^{\prime}$-dichlorofluorescein by horseradish peroxidase: possible implications for oxidative stress measurements. Free Radic Biol Med. 1999;27:873-81.

19. Lukes P, Dolezanova E, Clupek M, Jablonowski H, von Woedtke T, Reuter S. Kinetics of peroxynitrite formation and its decomposition in air plasma treated liquids. Proceedings of the 22nd International Symposium on Plasma Chemistry, 2015 July 5-10. ISPC 22. Antwerp (BE), 05.07.2015-10.07.2015. http://www.ispc-conference.org/ispcproc/ispc22/P-III-10-30.pdf

20. Wardman P. Fluorescent and luminescent probes for measurement of oxidative and nitrosidative species in cells and tissues: progress, pitfalls and prospects. Free Radic Biol Med. 2007;43:995-1022.

21. Buettner GH. The pecking order of free radicals and antioxidants: lipid peroxidation, $\alpha$-tocopherol and ascorbate. Arch Biochem Biophys. 1993;300:535-43.

Volume 6, Issue 1, 2016 